\title{
Kamchia watershed groundwater recharge assessment by the CLM3 model
}

\author{
Olga Nitcheva ${ }^{1, *}$ Borislav Milev ${ }^{2}$, Tanya Trenkova $^{3}$, Nina Philipova ${ }^{1}$ and Polya Dobreva ${ }^{1}$ \\ ${ }^{1}$ Institute of Mechanics at the BAS, Acad. G. Bonchev 4, 1311 Sofia, Bulgaria \\ ${ }^{2}$ European Politechnical University, St.St. Kiril i Methody 23, Pernik, Bulgaria \\ ${ }^{3}$ National Institute of Geophysics, Geodesy and Geography at the BAS, Acad.G. Bonchev 3, 1113 \\ Sofia, Bulgaria
}

\begin{abstract}
Estimating groundwater recharge is an important part of the water resources evaluation. In spite of the numerous existing methods it continues to be not easy value to quantify. This is due to its dependence on many meteorological, hydrogeological, soil type and cover conditions and the impossibility for direct measurement. Employment of hydrological models in fact directly calculates the influence of the above cited natural factors. The Community Land Model (CLM3) being loaded with all land featuring data in global scale, including an adequate soil filtration process simulation by the Richards equation, together with the possibility for input of NCEP/NCAR Reanalyses database, featuring the meteorological effect, gives an opportunity to avoid to great extent the difficulties in groundwater (GW) recharge estimation. The paper presents the results from an experiment concerning GW recharge monthly estimation during 2013, worked out for the Kamchia river watershed in Bulgaria. The computed monthly and annual values are presented on GIS maps and are compared with existing assessments made by other methods. It is proved the good approach and the applicability of the method.
\end{abstract}

\section{Introduction}

The GW is a part of the regions total runoff and the knowledge of their quantity enables their more rational utilisation from resource and environmental aspect.

The target of the paper is to analyse the possibilities of application of present-day advanced hydrology models, in particular the model CLM3, to assessment of the groundwater recharge.

\footnotetext{
* Corresponding author: olgani@imbm.bas.bg
} 


\section{Methodological aspects and methods for groundwater recharge evaluation}

The groundwater bodies (GWB) in fact are underground reservoirs which are mainly recharged through the surface by precipitation or other artificially created sources as irrigation losses and others. The re-infiltration through the banks of rivers, occurring in periods of high water levels, is significant only for GWB in the terraces along big rivers with sustained high water levels, not typical for mountainous countries like Bulgaria. This doesn't relate to the East Kamchia lowland GWB either.

The annual runoff from a catchment is composed of the surface component of the runoff occurred in a short period after the rainfall and the groundwater one formed by the GWB discharge known as base flow. Regarded in a multiannual period the volume of the base flow and that of the abstracted water should be equal to the volume of the recharge during that time interval.

The advantage of GW use compared to the surface running waters is their regulated character, i.e. the abstraction rate does not depend from the recharge rate, due to the water accumulation in underground reservoirs. Besides, they are broadly available away from running waters. In addition, groundwater resources are less subjected to pollution.

The currently used methods for GW recharge assessment apply two possible approaches for solution of this problem. The first one consists in calculation procedures for evaluation of the GW actual recharge rate based on the records of the long term variation of the GWB regime characteristics as their water table fluctuation or springs discharge, as well as of the streamflow regime of the linked with them rivers [1]. The ground water level fluctuation and the rivers streamflow separation methods use this approach. Its advantage consists in the lack of necessity for possessing data concerning the soil properties, land cover and relief and climatic effects. That can be considered as conventional methods. They have been developed and used broadly since the second half of the last century.

In the last two decades an often practice for GW recharge assessment became the employment of models accounting for the meteorological loading [2-6]. Here considered is an improved hydrological model, which includes adequate simulation not only of the surface runoff formation and evaporation but also of the processes of water infiltration and transport through the soil unsaturated zone. Thus it became possible the direct imitation of the entire process of water penetration into the soil depth forming the potential recharge through further percolation to the GWB. Using these models gives a new alternative instrument for GW recharge assessment. Their application doesn't need input of GWB related information but requires accurate knowledge about all factors forming the GW like the soil unsaturated zone water retention and filtration properties, land surface topographic and vegetation cover data and detailed long term records of the registered climatic factors. This information relates to the entire GWB watershed area. All these data apart from assessment of the soil water problems are commonly used in different fields of human activity wherefore they are expected to be easily available. Soil properties can be provided from soil maps used in the agriculture.

The model used in this study is the Community Land Model version 3.0 (CLM3). It is the land surface model of the Community Earth System Model and the Community Atmosphere Model (http://www.cgd.ucar.edu/tss/clm/) [2-3]. It is a spatially distributed model developed in the USA National Center for Atmospheric Research (NCAR). The model computes the water balance between the precipitation, runoff, evapotranspiration and infiltration through the soil layer simulating the processes of water and heat transport through the soil profile and energy exchange between the soil surface and the atmosphere. 
Regarded is a soil layer of given thickness made of joining to each other vertical columns with cross section equal to the area of the assumed spatial grid elements.

The main advantage of the assumed in this study model compared to other hydrological models is the detailed and realistic description of the water movement processes through the unsaturated zone by accurate mathematical dependencies. They account not only for the gravity but as well the porous and capillary uplift forces driving the soil moisture down or up the soil profile. The uplift forces depend on the degree of the wetness.

Numerical simulation of water transport in the soil zone is presented by the Richards equation [7], where the water transport in the soil profile depends on the wetness of the environment. This is the following nonlinear equation:

$$
C(\psi) \frac{\partial \psi}{\partial t}=\frac{\partial}{\partial z}\left[K(\psi)\left(\frac{\partial \psi}{\partial z}+1\right)\right]-S(\psi, z)
$$

In (1) $C(\psi)=d \theta / d \psi$ is the differential water capacity (water retention), $\theta$ is the volumetric soil moisture $\left(\mathrm{m}^{3} / \mathrm{m}^{3}\right), K(\psi)$ is the hydraulic conductivity ( $\mathrm{m} /$ day), $\psi$ is the soil water pressure head (m) (soil suction), $t$ is the time (days), $S(\psi, z)$ is the function of root water uptake $\left(\right.$ day $\left.^{-1}\right)$.

The Darcy-Richards equation (1) can be computed for the current time step $n+1$ after determining the moisture retention $\theta(\psi)$ and the hydraulic conductivity $K(\psi)$. It means for every time step $n$ after determination of $\psi$, the values of $C(\psi)$ and $K(\psi)$ are evaluated. So for the time step $n+1$, the partial differential equation of second order becomes a linear equation.

In the CLM3 model the soil hydraulic properties $C(\psi)$ and $K(\psi)$ are estimated by the empirical functions of Clapp and Hornberger [8].

\section{Kamchia River watershed description}

Bulgaria is a mountainous country with not abundant but regulated in many reservoirs surface waters (Fig. 1). They satisfy the needs of the irrigation and a greater part of the domestic and industrial water supply. Yet the groundwater serves as basic water source in flat regions with scarce possibilities for water accumulation reservoirs. The groundwater is important for meeting the water demand of the population in the Kamchia River region too.

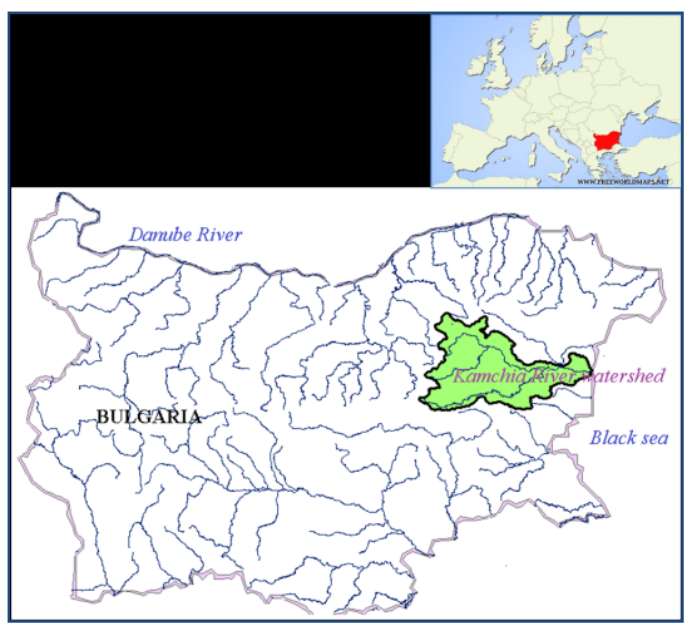

Fig.1. Map of Bulgarian territory and location of the Kamchia River watershed. 
The Kamchia River is $244.5 \mathrm{~km}$ long situated in eastern Bulgaria and is the longest river on the Balkan Peninsula flowing directly into the Black Sea [9-10].

Its watershed occupies the middle east part of the country, from Eastern Balkan to the Black Sea. Its area is $5358 \mathrm{~km}^{2}$ [10]. The west part is hilly with elevation from 700 to 300 $\mathrm{m}$. Towards the east to the Black sea the relief becomes flatter. In the west part the average annual precipitation is $750-800 \mathrm{~mm} / \mathrm{a}$, in the east part - about $550 \mathrm{~mm} / \mathrm{a}$. The climate is continental, the maximum river runoff occurs usually in February [9-10].

Kamchia River has considerable discharge contribution into the Bulgarian Black Sea, ranging between $179,3 \times 10^{6} \mathrm{~m}^{3} \mathrm{yr}^{-1}$ and $1475,3 \times 10^{6} \mathrm{~m} 3 \mathrm{yr}^{-1}$ [11]. It is the total amount of surface and groundwater resource.

The Kamchia River hydrogeology is presented by porous, carst (carst-ctack) and crack waters, which are differentiated by 12 groundwater bodies located in 6 geological layers Quaternary, Neogene, Paleogene, Upper Gretaceous, Hotriv Barem Gretaceous and Malm Valanginian (Fig.2) [12].

The porous groundwater occupy the first and second geological layers, while the carst, carst crack and crack groundwater are located in the third to sixth geological layers. The groundwater infiltration in some areas is very high, up to $30-40 \%$ of the precipitation. [13].

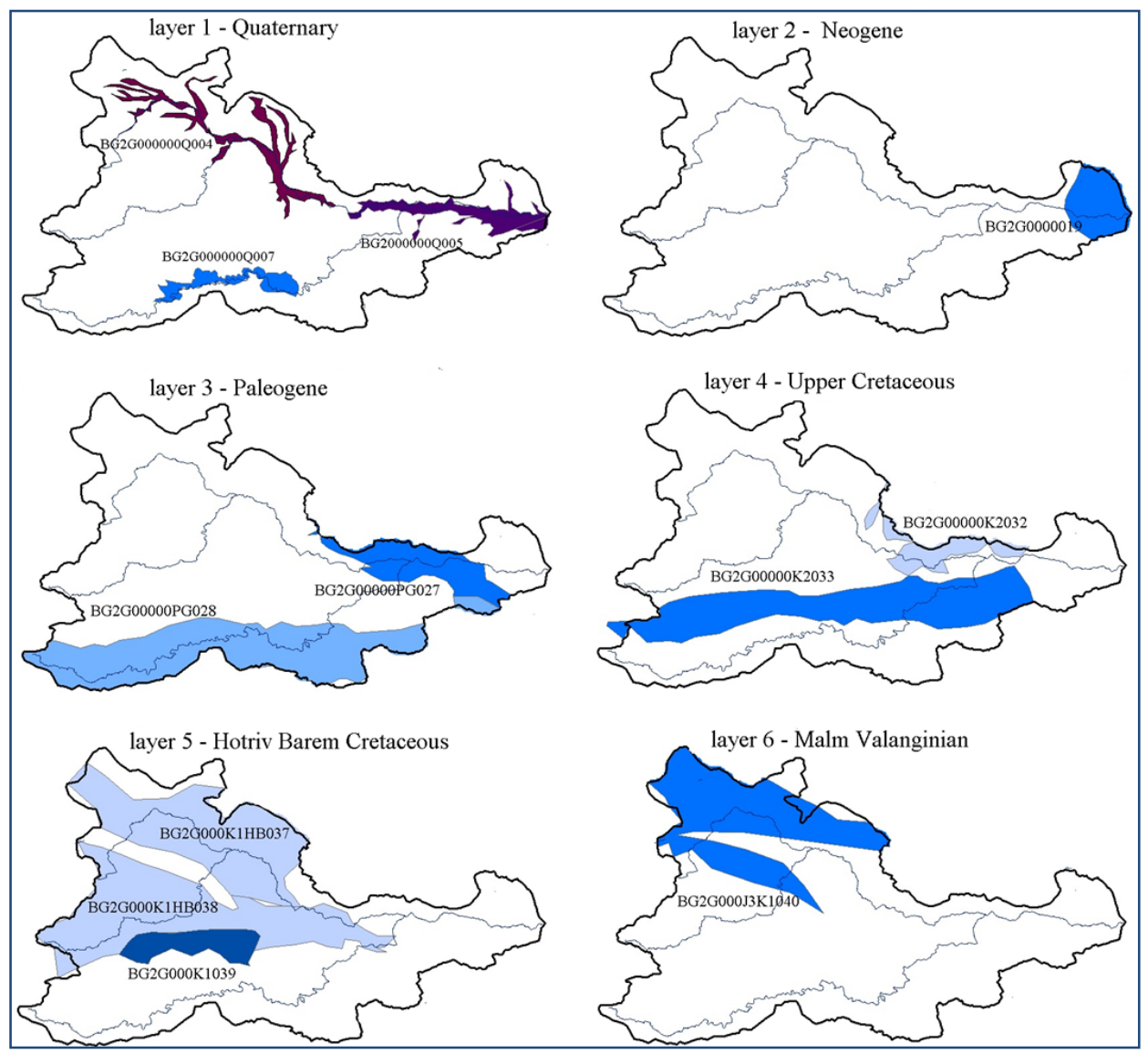

Fig. 2. Groundwater bodies location in 6 hydrogeological layers for the Kamchia River watershed. 
On the basis of the published in the Ministry of Environment and Water (MEW) site long term (for the period 1981-2013) [14] GWB annual recharge values the authors has prepared a GIS map showing the mean recharge intensity on all GWB watersheds in $\mathrm{mm}$. It is calculated through dividing the calculated by MEW mean annual GWB recharge in 1/s to the watershed area. The intensity on areas with overlaying GWB is obtained by superposition.

Given the complexity of the GWB multilayer location and scarcity of observation data records because of insufficient observation wells and springs and river discharge measurement stations as well, the elaborated map hardly can give reliable detailed information about the areal distribution of the recharge intensity. The following facts contribute to the approximate nature of the map. The plotted intensity is averaged over the GWB watersheds varying from several dozens to several thousand $\mathrm{km}^{2}$.

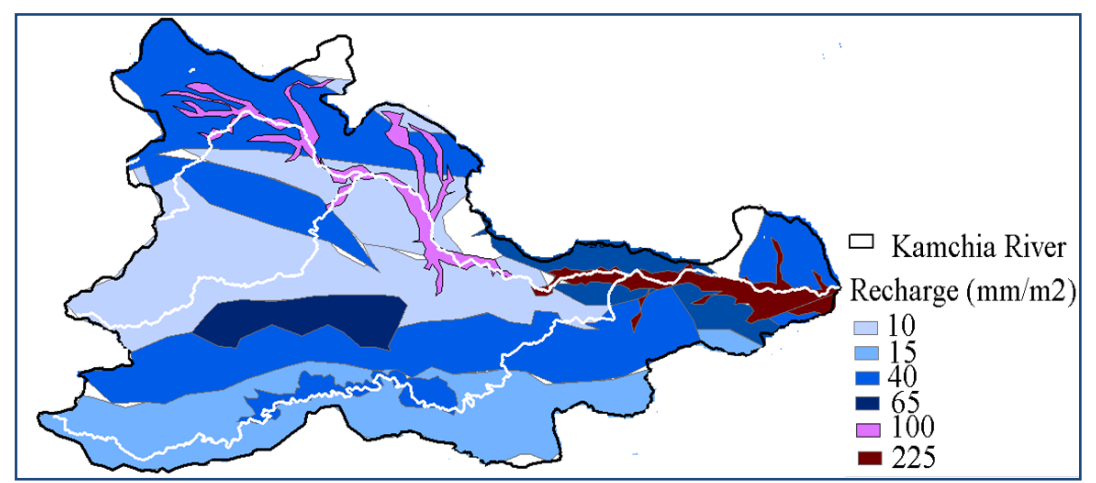

Fig. 3. Mapping the observed multi-annual groundwater recharge (by conventional methods) for the Kamchia River watershed through the period 1981-2013.

The shown on the map intensities in average are lower than real ones because the actual recharge areas of many GWB are less than their watersheds.

Nevertheless, the map is based on estimations using actual field data and regardless the above pointed out discrepancies with the lack of more trustworthy documents it can be used for various GWB related assessments.

\section{Groundwater recharge estimation by CLM3 model}

The CLM3 model is applied to evaluation of the GW recharge of the Kamchia River watershed during the year 2013. The year 2013 is characteristic with having country annual precipitation $638 \mathrm{~mm}$ nearly the same as the average precipitation for the period 1981-2013 [15]. For the studied region available are mean precipitation data measure in 12 meteorological stations - Omurtag $(714 \mathrm{~mm})$, Targovishe $(646 \mathrm{~mm})$, Shumen $(598 \mathrm{~mm})$, Koutel (794 mm), Preslav (641 mm), Smiadovo (678 mm), Varbitza (708 mm), Sindel (562 $\mathrm{mm})$, Dalgopol (646 mm), St. Oriahovo $(578 \mathrm{~mm})$, G. Chiflik $(534 \mathrm{~mm})$ and Obzor (594 $\mathrm{mm})[9,10]$, the average precipitation is $641,1 \mathrm{~mm}$.

The land surface grid in the study is assumed with resolution (cells) $5 \times 5 \mathrm{~km}$. Every cell input contains specific for its water movement and transformation related properties data according to the topography, land cover, soil profile and vegetation [16].

The needed by the model meteorological input is supplied in this study with NASA atmosphere NCEP/NCAR Reanalysis data gathered by weather observations from ships, planes, RAOBS, stations, satellite observations and other ways [17]. They are freely 
available and easy to use. The atmospheric forcing data as air temperature, air pressure and humidity, solar radiation, wind speed, precipitation with 1 day time step are applied to the nodes of computational grid with cells $200 \times 200 \mathrm{~km}$. In the cell they are continuously distributed. The mean annual precipitation on the Kamchia River watershed for 2013 computed by the model meteorological input is $681 \mathrm{~mm}$ (Table 1), very close to the MEW estimation as mean of the period 1981-2013.

The necessary input related to the country territory soils characteristics and land cover for every grid cell with resolution $5 \times 5 \mathrm{~km}$ are taken from the International Geosphere Biosphere Programme (IGBP) data base [16].

The simulation period started two months before the beginning of the study period - on 1.11.2012, in order the soil moisture distribution to reach the state of real initial field conditions. The latter is important because the actual soil wetness is the main factor for the soil unsaturated zone water transport considered in the model. The soil infiltration capacity is controlled by soil properties and soil moisture within the top soil layers.

The regarded in the model soil layer thickness is equal to $3.43 \mathrm{~m}$ divided into $10 \mathrm{sub}$ layers. The computation is executed in 3 hour time step. The water amount calculated as filtrated below the vegetation root zone, with assumed maximum thickness $1 \mathrm{~m}$, is considered as potential GW recharge. The model obtained potential recharge intensity monthly values for 2013, average for the whole district area, are shown in mm on Table 1. In the table the potential recharge intensity is named infiltration because it transforms into GW recharge only on a part of the watershed.

Table 1. Calculated monthly and annual hydrological parameters.

\begin{tabular}{|c|c|c|c|c|c|c|c|c|c|c|c|c|c|}
\hline Months & I & II & III & IV & V & VI & VII & VII & IX & X & XI & XII & $\mathbf{2 0 1 3}$ \\
\hline $\begin{array}{c}\text { Rain } \\
\text { (mm) }\end{array}$ & 23 & 57 & 28 & 44 & 55 & 159 & 82 & 22 & 26 & 58 & 53 & 8 & $\mathbf{6 1 5}$ \\
\hline $\begin{array}{c}\text { Snow } \\
\text { (mm) }\end{array}$ & 46 & 5 & & & & & & & & & 3 & 12 & $\mathbf{6 6}$ \\
\hline $\begin{array}{c}\text { Prec. } \\
\text { (mm) }\end{array}$ & 69 & 62 & 28 & 44 & 55 & 159 & 82 & 22 & 26 & 58 & 56 & 20 & $\mathbf{6 8 1}$ \\
\hline $\begin{array}{c}\text { Infiltr. } \\
\text { (mm) }\end{array}$ & 20 & 51 & 3 & 7 & -17 & 53 & -14 & -27 & 2 & 24 & 36 & 13 & $\mathbf{1 5 1}$ \\
\hline $\begin{array}{c}\text { Infiltr./ } \\
\text { prec. } \\
\text { (\%) }\end{array}$ & 29 & 82 & 11 & 16 & & 33 & & & 8 & 41 & 64 & 65 & $\mathbf{2 2}$ \\
\hline
\end{tabular}

From the results shown on Table 1 the following conclusions are possible to draw. The estimate of the district territory mean annual infiltration intensity in percent of the total annual precipitation is $22 \%$. The monthly distribution of the infiltration quantities in response of the precipitation is rather logical. In cold but not frosty months in the period October-February the infiltration share of the precipitation is high while in the warm and hot period March - September the prevailing movement of soil water is upward due to capillary uplift forces. An exception happens in June when the precipitation is very high. The annual infiltration is $151 \mathrm{~mm}$.

The shown infiltration turns into potential GW recharge only on the $2000 \mathrm{~km}^{2}$ of the whole district estimated by the National Hydrogeological Map [19]. If so the total annual recharge for 2013 on the Kamchia River Watershed can be evaluated as equal to $2000 \times 10^{6}$ x $0,151=302 \times 10^{6} \mathrm{~m}^{3}$. 
The groundwater recharge of the country makes $30-50 \%$ of the total river runoff. It is observed that for Bulgaria for the period 1981-2013 the average annual total runoff amounts to $15495 \times 10^{6} \mathrm{~m}^{3}$ while the average annual groundwater recharge is $5421 \times 10^{6}$ $\mathrm{m}^{3}$ [15] the ratio being $35 \%$. There is no information about the GW recharge to total runoff ratio of the Kamchia River watershed. Assessed by hydrometric observations the Kamchia River mean annual runoff is approximately $829 \times 10^{6} \mathrm{~m}^{3}$ [9-10]. The modelled groundwater annual recharge, estimated for an year with precipitation close to the average one for the watershed, is equal to $36,4 \%$ of the mean annual runoff. It is close to the total country one $35 \%$. This proves to a great measure the realism of the model recharge estimations.

The CLM3 model calculates the average infiltration intensity on every grid cell with 25 $\mathrm{km}^{2}$ area. This enables the authors to plot a GIS map [20] of the territorial distribution of the annual infiltration intensity of the Kamchia River watershed for the regarded year shown on Fig. 4. The map could be matched to the analogous map on Fig. 3. Their similarity consists in the fact that they both show the recharge intensity distribution on the district territory under approximately equal annual precipitation. On the other hand, there are substantial differences between them having in mind the described at the end of the previous paragraph way of obtaining the map on Fig. 3. The information on the map on Fig. 3 is a result of averaging and approximate assessments based on lump figures taken from the MEW published data [14], while the map on Fig 4 is directly based on computation values. This relates above all to the map resolution and infiltration intensity values. While the map on Fig. 3 gives more or less a rough picture of the district GW recharge territorial distribution the one on Fig. 4 shows the computed values on every land spots with equal to $25 \mathrm{~km}^{2}$ area. The numbers on the map on Fig. 3 are more or less fictitious values, obtained by dividing the real GWB recharge volume to the GWB entire watershed area, while the map on Fig. 4 shows the value of the computed spot infiltration intensity. Therefore, a detailed comparison between them is not relevant.

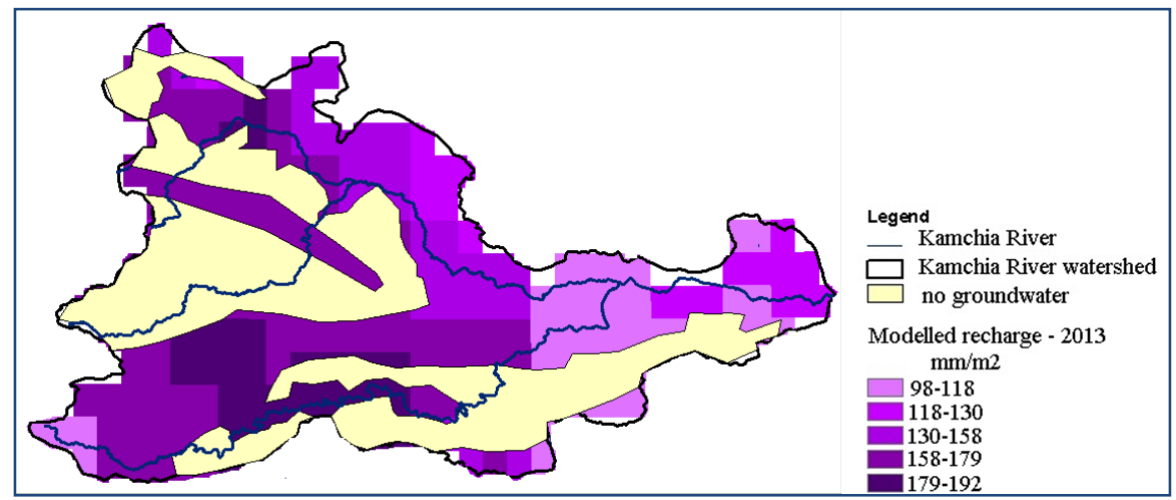

Fig. 4. Mapping the modelled annual groundwater recharge for the Kamchia River watershed in 2013.

The results of the comparison between the two maps obtained by completely different methods and data sources lead to two basic conclusions. The first is that the model CLM3 rather well reflects quantitatively the soil moisture infiltration processes and the assumption of the water infiltrated below the $1 \mathrm{~m}$ root zone as potential recharge is realistic. The second very important conclusion is that the huge amount of the model input related to the land surface, soil characteristics and climatic effects is correct and trustworthy as a whole. There is always possibility with peer analysis of the results from the model application to single GWB recharge simulation to achieve further calibration of the soil and land cover related data sets concerning some of the grid cells. 


\section{Conclusions}

So far no hydrogeological modeling of the Kamchia River watershed has been done. The executed study is an innovative one. The results from the modeling have been compared to the scarce existing observation data.

A simulation has been done for the year 2013 with precipitation close to the average value for the period 1981-2013. The obtained GW recharge can be assumed as average value for the last 32 years. The total annual recharge amounts to $151 \mathrm{~mm}$ equal to $22 \%$ of the annual precipitation quantity.

GW recharge intensity GIS maps have been prepared based on the available data drawn from the MEW database as well as on the results from the modeling. The results from their comparison are commented.

The model obtained annual GW recharge of the Kamchia River watershed equal to 302 $\times 10^{6} \mathrm{~m}^{3}$ makes $36,4 \%$ of the mean annual river runoff amounting to $829 \times 10^{6} \mathrm{~m}^{3}$. The percentage is rather close to the same value valid for the whole country and equal to $35 \%$.

The estimated GW recharge intensity varies from $98 \mathrm{~mm}$ to $192 \mathrm{~mm}$ on the areas with possibility for infiltration. It is established by observation that on some areas the GW recharge reaches up to $30-40 \%$ of the precipitation. This confirms the high values obtained by the modeling.

The accomplished study can serve as basis for prognostic assessments of the GW recharge response to climate changes under given scenarios.

\section{References}

1. NIMH, Methodology for assessment of the groundwater body resources with consideration of the climatic factors changes and the necessary water quantity monitoring for its accomplishment, 2012

2. K. Oleson et al, NCAR Tech. Note NCAR/TN-461+STR, Natl. Cent. for Atmos. Res., Boulder (2004)

3. K. Oleson, G. Niu, Z. Yang, D. Lawrence, J. Geophys. Res. (113) 2008

4. L. Pagliero, F. Bouraoui, P. Willems, J. Diels, Journal of Env. Quality 43, 145 (2014)

5. A. Pistocchi, H. Bek, B. Bisselink, E. Gelati, C. Lavalle, J. Feher, Water scenarios for the Danube River Basin, JRC Technical Report (2015)

6. I. Trichakis, P. Burek, A. deRoo, A. Pistocchi, Environ Process J. 15, 1 (2017)

7. L. Richards, Journal of Applied Physics 1, 318 (1931)

8. B. Cosby, M. Hornberger, B. Clapp, T. Ginn, Water Resources Research J. 20 (6), 682 (1984)

9. O. Santurdjian et al, General schemes for water use in the districts with river basin management of Bulgaria, IWP BAS (2000)

10. O. Santurdjian et al, Waters in the Kamchia River Basin, IWP (2006)

11. S. Dineva, International Symposium on Outfall Systems, Mar del Plata, Argentina (2011)

12. Ministry of Environment and Water of Bulgaria, River Basin Management Plans for Black Sea Region, 2010-2015, http://www.bsbd.org/UserFiles/File/RAZDEL_1(1).pdf

13. Environmental Assessment Report „Preparation of a general transport master plan of R. Bulgaria", Ministry of transport, information technologies and communications of Republic of Bulgaria (2010) 
14. Ministry of Environment and Water of Bulgaria, Registry of the resources and balans of the groundwater of the Black Sea basin Directorate (2015)

15. Ministry of Environment and Water of Bulgaria, Multiannual fresh water resources of Bulgaria up to 2013, http://www5.moew.government.bg/?page_id=24269

16. G. Bonan, S. Levis, L. Kergoat, K. Oleson, Global Biogeochem. Cycles J. 16 (2), 5 (2002)

17. E. Kalney et al, Bull. Amer. Meteor. Soc J. 77, 437 (1996)

18. O. Nitcheva, B. Milev, Journal of Theoretical and Applied Mechanics 47 (1), 85 (2017)

19. Maps, Atlas of Bulgaria, published by the Geographycal Institute of Bulgarian Academy of Sciences (1973)

20. A. De Jager, J. Vogt, Hydrol. Sci. J. 55 (5), 661 (2010) 